\title{
Erratum: "Principles of Mathmodelica" [Automatic Documentation and Mathematical Linguistics 42 (1), 45 (2008)]
}

O. G. Taits

Received June 2, 2008

DOI: $10.3103 / \mathrm{S} 0005105508031016$

Regarding the article "Principles of Mathmodelica," Automatic Documentation and Mathematical Linguistics, Volume 42, Number 1, February, 2008 by O.G. Taits, Allerton Press, Inc. and Springer-Verlag GmbH have recently learned that MATHMODELICA ${ }^{\mathrm{TM}}$ is in fact a trademark owned and in many countries registered by the Swedish company Mathcore Engineering AB. For purposes of clarification we hereby want to stress the fact that Mathcore Engineering $\mathrm{AB}$ has no, and has had no, connection whatsoever with the aforementioned author or his article. 